\title{
Geometria dinâmica no ensino de transformações no plano
}

\author{
Margarete Medeiros Maria Gravina
}

\begin{abstract}
Resumo
Este artigo trata de uma experiência didática com foco nas transformações geométricas no plano e no uso do ambiente de geometria dinâmica GeoGebra. A experiência, na forma de oficina, foi com professores do Ensino Fundamental. Tendo como conteúdo matemático as transformações geométricas, a proposta integrou geometria e arte através da construção de pavimentações do plano e de mosaicos de Escher. O trabalho foi desenvolvido dentro dos princípios da Engenharia Didática e, para a realização das análises, usamos a teoria sócio-histórica, cuja referência principal é a obra de Vygotsky e, também, a teoria dos registros de representação de Duval, que trata do processo de aprendizagem da matemática sob o ponto de vista da semiótica. A partir das análises foi possível constatar que os professores participantes se apropriaram dos recursos e do sistema de representação que se tem no GeoGebra, bem como dos conceitos da geometria das transformações.
\end{abstract}

Palavras-chave: Transformações Geométricas; Arte; Geometria Dinâmica.

\section{Abstract}

This article deals with a didactic experience focusing on geometric transformations in the plane and use of the GeoGebra dynamic geometry environment. The experience, in the form of a workshop, was performed with elementary school teachers. Having as mathematical content the geometric transformations, the proposal integrated geometry and art through the construction of tessellation and Escher mosaics. The work was developed within the principles of Didactic Engineering and, for the accomplishment of the analyzes, we use the social-historical theory, whose main reference is the work of Vygotsky and also the theory of the records of representation by Duval, that deals with the process of learning of Mathematics from the point of view of semiotics. From the analysis, it was possible to verify that the participating teachers appropriated the resources and the system of representation that one has in GeoGebra, as well as the concepts of the geometry of the transformations.

Keywords: Geometric transformations; Art; Dynamic geometry.

\section{Introdução}

O objetivo da oficina foi fazer a formação de professores para o uso de tecnologias, com concomitante aprendizagem de conceitos da geometria das transformações. Também tivemos como 
propósito desencadear um processo multiplicador de uso de tecnologia na escola - aos nossos alunos, então professores, caberia transpor para as suas salas de aula a experiência vivida ao longo da oficina. Assim estaríamos também provocando possibilidades de mudanças nas práticas pedagógicas, quando os professores nelas incorporam as tecnologias.

A oficina tratou de discutir novas formas de trabalhar a geometria escolar. Para isto, escolhemos o software de geometria dinâmica GeoGebra ${ }^{1}$, uma ferramenta com consistente organização de conteúdos e menus, e produzida dentro da filosofia do software livre. Escolhemos o tema das transformações geométricas no plano e pavimentações, porque este é um assunto fortemente sugerido nos Parâmetros Curriculares Nacionais (PCN), a ser trabalhado a partir das séries finais do Ensino Fundamental. Feita as escolhas, lançamo-nos nas leituras e reflexões que subsidiaram a concepção e implementação da experiência de formação de professores. Neste artigo apresentamos um recorte de tal proposta. O trabalho completo encontra-se na dissertação de mestrado "Geometria Dinâmica no Ensino de Transformações no Plano - uma experiência com professores da Educação Básica" "2 apresentada pelo primeiro autor do artigo no Programa de Pós-Graduação em Ensino de Matemática do Instituto de Matemática da UFRGS.

\section{Algumas reflexões teóricas}

De acordo com [15], nos últimos anos tem existido um crescente interesse pelo estudo da semiótica no campo da Educação Matemática. Segundo este pesquisador, diferentes são as razões que justificam esse interesse. Uma primeira razão diz respeito à tomada de consciência de que a atividade matemática é essencialmente uma atividade simbólica, e nesta direção ele menciona o trabalho de [6] sobre registros de representações. Uma segunda razão está na importância da compreensão da natureza do discurso matemático, no qual a semiótica aparece como uma teoria apropriada para dar conta da sua complexidade. Uma terceira razão se refere ao uso cada vez maior da tecnologia digital no ensino da matemática, e aqui a semiótica ajuda a entender o potencial das novas representações dinâmicas, disponíveis em diferentes softwares. E, por último, [15] destaca que a tecnologia e os signos são portadores de convenções e formas culturais de significação que fazem da semiótica um campo importante de pesquisa. Os trabalhos que hoje tratam de semiótica e aprendizagem da matemática, como aqueles de Radford e Duval, tem avançado com importantes contribuições sobre funcionamentos cognitivos que acompanham os processos de aprendizagem e as dificuldades que lhe são inerentes.

Apoiando-nos nas razões elencadas acima, decidimos tomar como embasamento teórico de nosso trabalho as ideias de Vygotsky, que já nos anos 30 tratavam da importância dos signos na construção do conhecimento. Nossas reflexões sobre os diferentes conceitos que estão na teoria de Vygotsky foram feitas a partir de publicações de diferentes autores (Ivic, 2010; [1], [11], [14], [15], [12]). Procuramos evidenciar o potencial da teoria sócio-histórica na construção das bases de propostas de ensino que visemo desenvolvimento cognitivo dos indivíduos e consideramos que os conceitos de interação social, mediação, interiorização e zona de desenvolvimento proximal podem ser norteadores de escolhas de procedimentos educativos. De acordo com Ivic (2010) nenhuma teoria psicológica do desenvolvimento confere tanta importância à educação quanto a de Vygotsky. Este autor também enfatiza que as referências à educação escolar que encontramos na obra de Vygotsky devem ser

\footnotetext{
${ }^{1}$ GeoGebra é um software de matemática dinâmica e multiplataforma de livre distribuição que pode ser encontrado no site www.geogebra.org.

${ }^{2}$ Disponível em http://www.lume.ufrgs.br/handle/10183/54888.
} 
consideradas não como descrições das realidades educacionais, mas como propostas para renovar a educação.

Segundo Moll ([12]), Vygotsky afirma que "o fato central em nossa psicologia é o da mediação". É fato que nas nossas atividades utilizamos instrumentos que atuam como mediadores, dentre os quais se destacam as ferramentas e os signos. Segundo Moysés ([14]), no caso da aprendizagem da Matemática, muitos são os instrumentos que podem atuar como mediadores - por exemplo, a linguagem oral e escrita, os objetos concretos do mundo físico, os objetos virtuais como softwares. Radford ([15]) destaca a função mediadora dos signos na reconstrução da ação que leva a internalização do saber. Já Mariotti ([11]) afirma que a internalização do saber também depende de intercâmbios sociais que fazem uso do registro especial de linguagem que é o 'discurso do professor' - o professor é um especialista na cultura matemática e pode atuar como um mediador no processo de desenvolvimento cognitivo do aluno.

Existem, pelo menos, dois níveis de desenvolvimento cognitivo identificados por Vygotsky: um real, já formado, o que significa que processos mentais já estão estabelecidos; e um potencial, ainda a acontecer, e que diz respeito a capacidade de aprender com outra pessoa. Ainda segundo Vygotsky, aprendizagem e o desenvolvimento estão inter-relacionados, e dependem das interações sociais que acontecem naquilo que ele denomina de zona de desenvolvimento proximal. Moysés ([14]) destaca que o trabalho na zona de desenvolvimento proximal exige a interação entre aluno e professor e que o aluno progride no seu processo cognitivo quando tem alguém que sabe pôlo a pensar. Radford ([15]) também descreve que Vygotsky em uma de suas palestras ${ }^{3}$ chamou a atenção para o fato de que o ser humano está imerso em mundo de dispositivos artificiais (artefatos) e que estes dispositivos alteram o curso do desenvolvimento natural dos processos psíquicos, indo além de simples dispositivos de auxílio; e além dos dispositivos físicos, existem os dispositivos abstratos, como por exemplo os sistemas semióticos. Duval ([6]) afirma que a pluralidade de sistemas semióticos permite uma diversificação das representações de um mesmo objeto e isso aumenta as capacidades cognitivas dos indivíduos e suas representações mentais. As representações mentais funcionam sempre em simbiose com os sistemas semióticos - a partir de nossa imagem mental criamos a representação que nos permite a comunicação e a partir da representação que já existe, interiorizamos novas imagens mentais.

A articulação dessas diferentes representações é condição para a compreensão em Matemática. É essencial não confundir o objeto matemático, como, por exemplo as retas, com suas representações, pois um mesmo objeto matemático pode ter muitas representações diferentes. "A análise do conhecimento não deve considerar apenas a natureza dos objetos estudados, mas igualmente a forma como os objetos nos são apresentados ou como podemos ter acesso a eles". [7, p15]. Duval ([7]) denomina registros ${ }^{4}$ as diferentes representações semióticas que se fazem presentes na Matemática. Os registros são sistemas cognitivamente produtores de possibilidade de criação de novo conhecimento e o autor classifica estes registros: as frases em língua natural, sendo este registro discursivo o primeiro registro para o funcionamento do pensamento; as equações; as figuras; os gráficos e os diagramas. Na aprendizagem da Geometria, diferentes são os registros utilizados: o registro em língua natural quando definimos os objetos geométricos; o registro figura quando desenhamos o objeto; o registro algébrico quando descrevemos os objetos por meio de equações.

Associada ao conceito de registro tem-se a noção de transformação de registro, também introduzida

\footnotetext{
${ }^{3}$ Em uma conferência em 1930 na Academia de Educação Comunista.

${ }^{4} \mathrm{O}$ emprego da palavra registro cristaliza a tomada de consciência de outro modo de funcionamento cognitivo do pensamento, modo mais potente para os matemáticos. Isso confere a essa palavra um valor teórico. [7].
} 
por [6]. Duas são as transformações: o tratamento e a conversão. O tratamento é a transformação de uma representação em outra, dentro de um mesmo registro - por exemplo, acrescentar elementos geométricos em figura que apoia uma argumentação. A conversão é a transformação de uma representação em outra dentro de novo registro; por exemplo, passar do registro em língua natural, quando definimos um objeto geométrico, para o registro figura quando desenhamos o objeto. $\mathrm{Na}$ próxima sessão vamos tratar dos diferentes registros que podem ser usados de forma simultânea no software GeoGebra.

\section{O potencial semiótico do software GeoGebra}

Faz tempo que muitos autores apontam para potencial da tecnologia digital no âmbito da Educação Matemática (Balacheff e Kaput, 1996; [3], [8], [2]). Pesquisas que atestam este potencial, em especial, quanto ao uso de softwares de geometria dinâmica já foram produzidas (Laborde, 1996; [8]). No entanto, a utilização destes softwares ainda não se faz presente, de forma sistemática, em nossas salas de aula. É na direção de contribuir para mudar esta realidade que foi desenvolvida a proposta de oficina de formação para professores para o uso do GeoGebra, com foco nas transformações geométricas e também em aspectos relativos à construção do conhecimento, quando se faz o uso de ambientes de geometria dinâmica.

O GeoGebra ${ }^{5}$ é um software gratuito, de livre acesso, de fácil instalação e utilização. A escolha deste software se deu, principalmente, pela sua interface dinâmica e pela versatilidade na realização de transformações de registros. O GeoGebra permite tratar a Álgebra e a Geometria com mesmo grau de importância, ao disponibilizar simultaneamente janelas para trabalhar nestas duas áreas. Ele apresenta diferentes tipos de registros semióticos: o algébrico, o geométrico e o discursivo. Por exemplo, conforme ilustra a Figura 1, ao colocarmos no campo Entrada a equação do círculo $x^{2}+y^{2}=9$, temos na Janela de Álgebra o registro algébrico; na Janela de Visualização tem-se o desenho do correspondente círculo, aqui o registro figura. Um outro modo de obter o círculo é escolher no menu a ferramenta Círculo dados Centro e Um dos seus Pontos e com esta escolha estamos trabalhando com o registro discursivo. No menu Exibir do GeoGebra tem-se o Protocolo de Construção (registro discursivo) que permite acompanhar o procedimento de construção de um objeto geométrico (registro figura). A Figura 2 ilustra estes diferentes registros no GeoGebra. Os exemplos apresentados acima ilustram de que forma diferentes ações feitas no GeoGebra propiciam o trabalho com os diferentes registros de representação elencados por Duval. E no caso do estudo da Geometria enfatizamos, em especial, a importância da mobilização de dois registros - o discursivo e a figura.

\section{Transformações geométricas e geometria dinâmica}

As transformações geométricas são funções que associam a cada ponto do plano, um outro ponto também do plano, obedecendo certas regras. Estamos aqui interessados nas isometrias, isto é, transformações que preservam distâncias. Se $\Pi$ e $\Pi^{\prime}$ são dois planos, uma transformação $T$ : $\Pi \rightarrow \Pi^{\prime}$ é uma isometria quando a distância entre os pontos $T(A)$ e $T(B)$ é igual à distância entre os pontos $A$ e $B$, para quaisquer pontos $A$ e $B$; ou seja, quando $d(T(A), T(B))=d(A, B)$ para quaisquer pontos $A$ e $B$. Do livro de Lima ([10, p13-14]) trazemos enunciados de algumas propriedades que nele estão demonstradas: a) Toda isometria $T: \Pi \rightarrow \Pi^{\prime}$ transforma retas em

\footnotetext{
${ }^{5}$ Disponível para download em www.geogebra.org. Neste site, que pode ser acessado em diversos idiomas, e nele tem-se mais informações sobre o GeoGebra.
} 
Arquivo Editar Exibir Opções Ferramentas Janela Ajuda

Entrar..

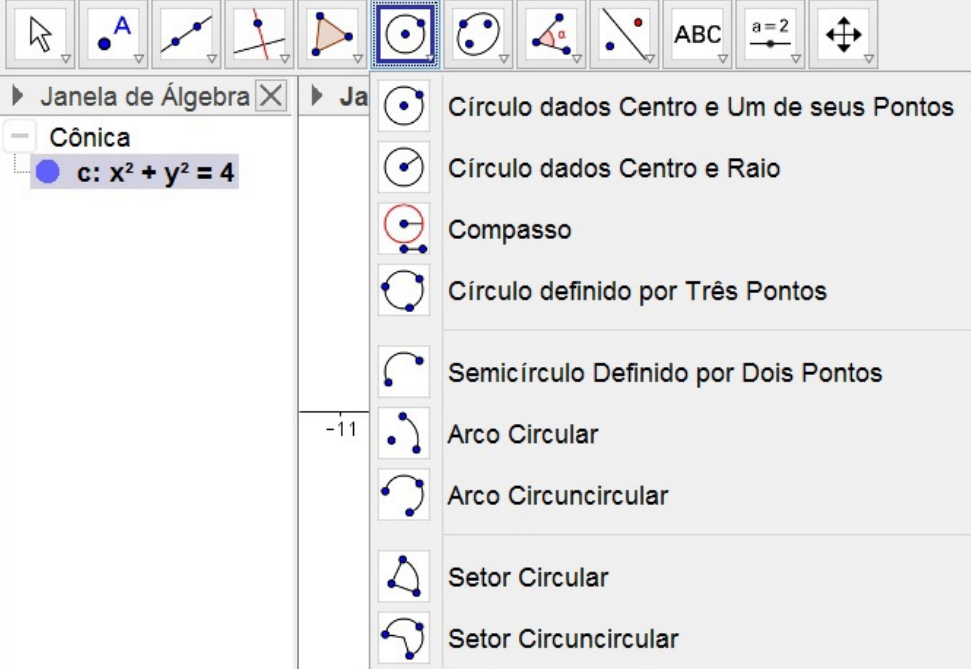

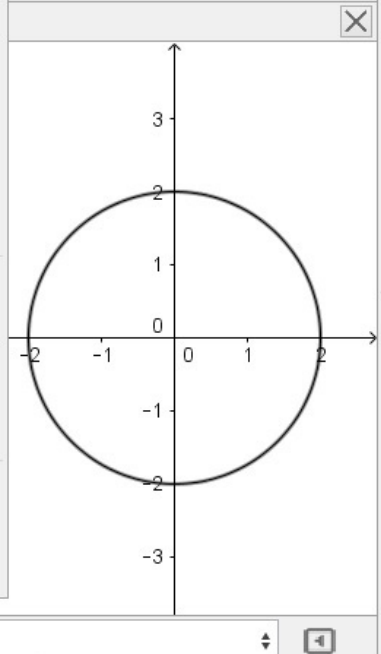

Figura 1: Registros de representação para o círculo.

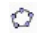

GeoGebra

Arquivo Editar Exibir Opções Ferramentas Janela Ajuda

Entrar...

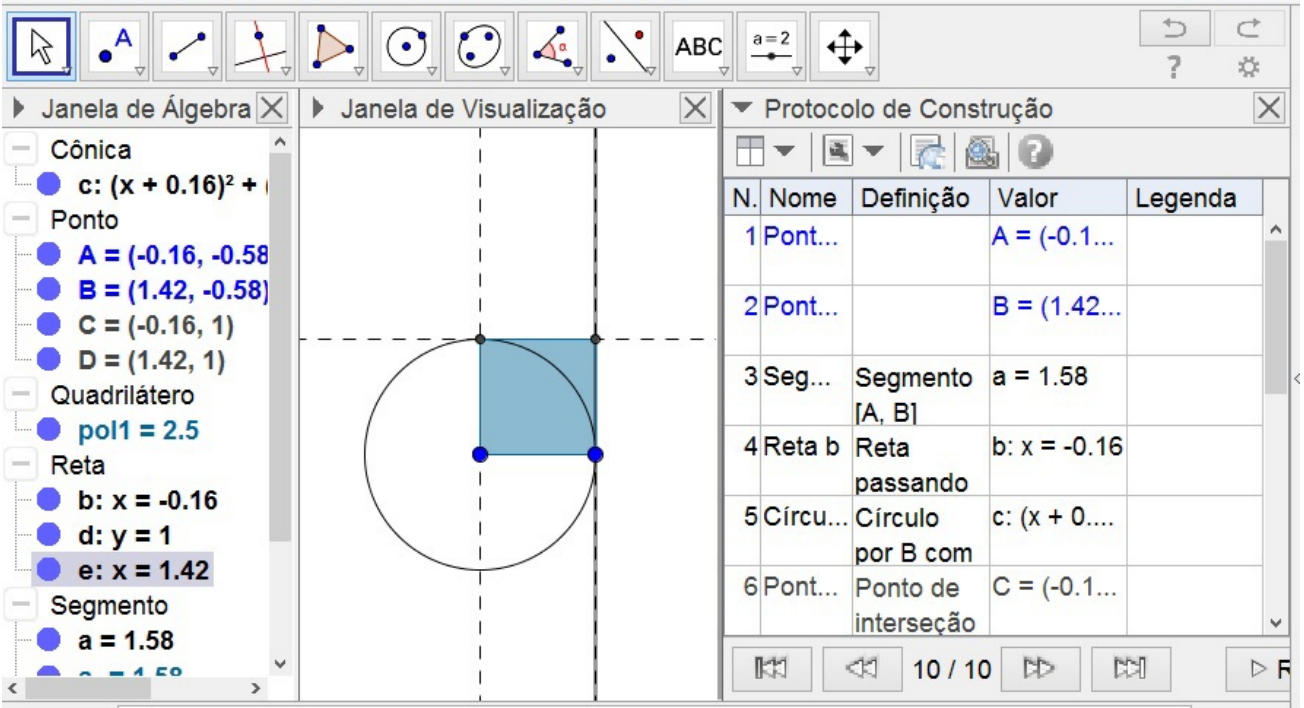

Figura 2: Construção do quadrado no GeoGebra. 
retas; b) Toda isometria $T: \Pi \rightarrow \Pi^{\prime}$ transforma retas perpendiculares em retas perpendiculares; $c$ ) Toda isometria $T: \Pi \rightarrow \Pi^{\prime}$ é uma bijeção, cuja inversa $T^{-1}: \Pi^{\prime} \rightarrow \Pi$ é ainda uma isometria; d) Toda isometria $T: \Pi \rightarrow \Pi^{\prime}$ transforma um ângulo em outro ângulo de mesma medida.

Pelo fato de uma isometria preservar segmentos, ângulos e suas medidas, tem-se que a imagem de uma figura $F$ por uma isometria é uma figura $F^{\prime}$ congruente à $F$. As isometrias que vamos tratar são: a translação, as reflexões segundo um ponto e segundo uma reta, e a rotação. Apresentamos a seguir as definições destas transformações, bem como as rotinas de uso no menu do GeoGebra, destacado na Figura 3.

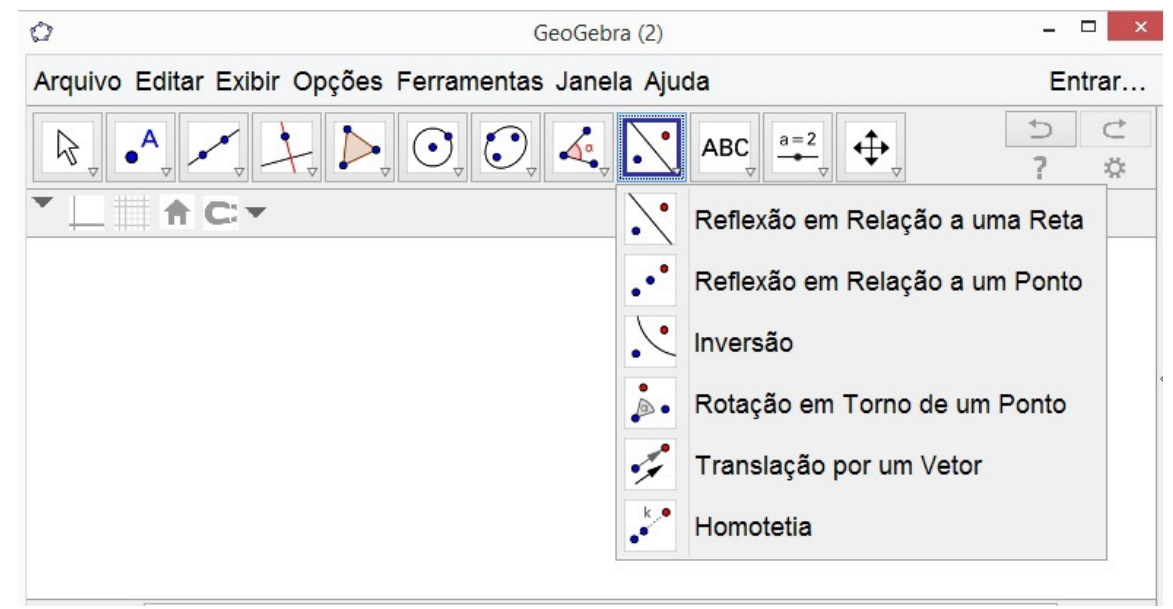

Figura 3: Menu das transformações geométricas no GeoGebra.

- A transformação de translação

A noção de translação está relacionada ao conceito de vetor (do Latin "vehere" = transportar). Um vetor é dado pela direção, sentido e comprimento de uma família de "setas" equivalentes. Na Figura 4 temos duas famílias de setas equivalentes, portanto indicando dois vetores. As setas das famílias são usadas para representar o vetor.
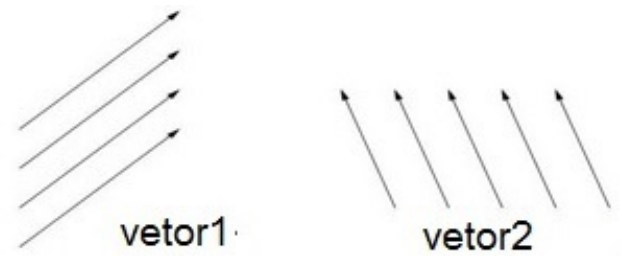

Figura 4: Representação de vetor no plano.

A translação determinada pelo vetor $v$, representado pela 'seta' $U V$, é a transformação que associa cada ponto $A$ do plano ao ponto $A^{\prime}$ de forma tal que: 
- se $A$ não pertence a reta determinada pela 'seta' $U V$, os pontos $A, A^{\prime}, V$ e $U$, nesta ordem, formam um paralelogramo,

- se $A=U$ então $A^{\prime}=V$; se $A$ é diferente de $U$ e pertence a reta determinada pela 'seta' $U V$ e, então $A^{\prime}$ pertence a mesma reta e é tal que as 'setas' determinadas pelos pontos $U$ e $A, V$ e $A^{\prime}$, respeitando esta ordem de correspondência, são equivalentes.

Na Figura 5 tem-se o ponto $A^{\prime}$ transladado do ponto $A$, segundo o vetor $v$.

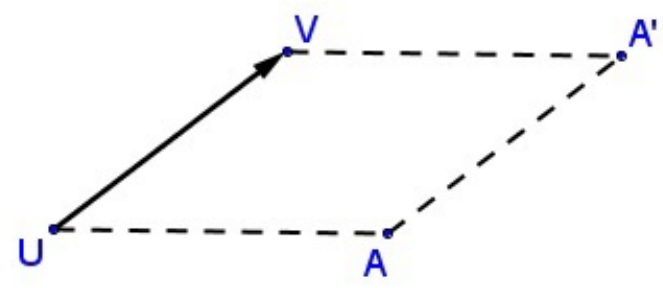

Figura 5: Translação do ponto $A$ segundo o vetor $v$.

A translação é uma isometria (isto se demonstra) e assim transforma qualquer figura em outra congruente. Na Figura 6 tem-se o vetor $u$ representado por uma seta, o triângulo $A B C$ e o triângulo $A^{\prime} B^{\prime} C^{\prime}$ que é o seu transladado. Para obter tal resultado no GeoGebra, o procedimento é: usando ferramenta do menu inicialmente constrói-se um Vetor u e depois com a ferramenta Polígono se constrói o triângulo $A B C$; com a ferramenta Translação por um Vetor seleciona-se o triângulo $A B C$ e após o vetor $u$ e então é produzido o triângulo $A^{\prime} B^{\prime} C^{\prime}$.

Com a ferramenta Mover pode-se mudar a posição dos vértices do triângulo $A B C$, e este movimento resulta em alteração no triângulo $A^{\prime} B^{\prime} C^{\prime}$, mas ele se mantém sempre um transladado do primeiro triângulo.

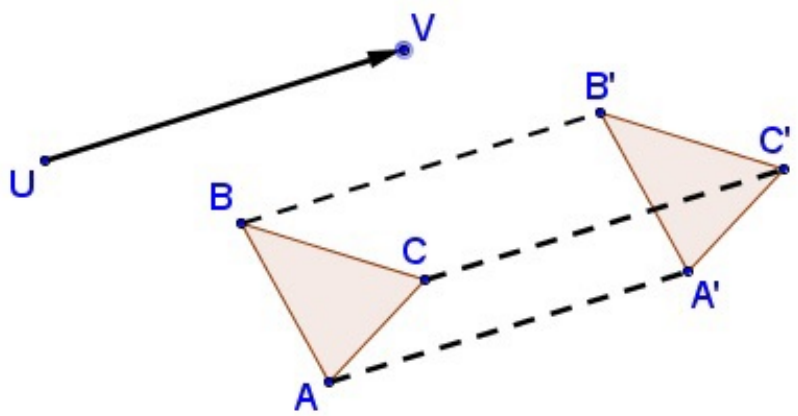

Figura 6: Translação do triângulo $A B C$ segundo o vetor $u$.

A Figura 7 ilustra sucessivas translações segundo um o mesmo vetor. Nesta construção, inicia-se com uma reta definida por dois pontos para dar a ideia de um 'cordão esticado'. Em seguida, com a ferramenta Polígono constrói-se um pentágono na forma de 'bandeirinha'. A partir deste pentágono 
são feitas sucessivas translações segundo um mesmo vetor (a seta está destacada na Figura 7, da primeira para a segunda 'bandeirinha') e, desta forma, se obtém coleção de 'bandeirinhas' coloridas. Ao ser aplicada a ferramenta Mover nos vértices do primeiro pentágono, todas as bandeirinhas se modificam, simultaneamente,mantendo-se congruentes, entre si.

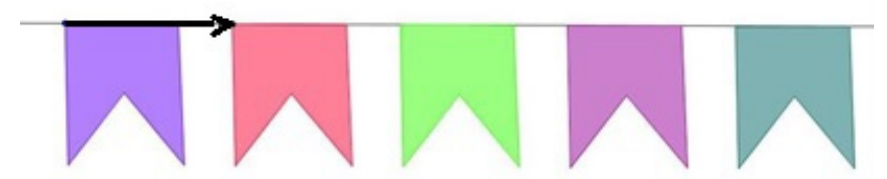

Figura 7: Sucessivas translações segundo um mesmo vetor.

- As transformações de reflexão

A reflexão de centro $O$ é a transformação geométrica que associa a cada ponto $A$ do plano, um ponto $A^{\prime}$ tal que

- se $A=O$ então $A^{\prime}=O$.

- se $A$ é diferente de $O$ então $A^{\prime}$ está na semi-reta oposta à semi-reta $O A$ e os segmentos $O A$ e $O A^{\prime}$ são congruentes.

Apresentamos na Figura 8 a reflexão segundo um ponto $O$, construída no GeoGebra, conforme o seguinte roteiro: inicia-se com a construção do ponto $\mathrm{O}$ centro da reflexão, depois constrói-se o ponto $A$ e então usando a ferramenta Reflexão em Relação a um Ponto seleciona-se o ponto $A$ e em seguida o ponto $O$.

Aparece então o ponto $A^{\prime}$, que é a reflexão de $A$ em relação ao ponto $O$ e pode ser observado que os segmentos segmentos $O A$ e $O A^{\prime}$ se mantém congruentes, ao aplicar-se Mover no ponto $A$.

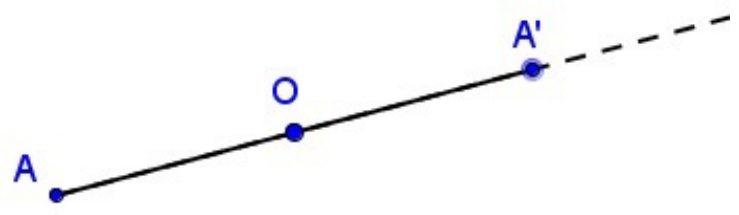

Figura 8: Reflexão do ponto $A$ em torno do ponto $O$.

A reflexão segundo a reta $r$ é a transformação geométrica que associa a cada ponto $A$ do plano, um ponto $A^{\prime}$ tal que:

- se o ponto $A$ pertence a reta $r$, então $A=A^{\prime}$.

- se o ponto $A$ não pertence a reta $r$, então $A^{\prime}$ pertence a reta perpendicular à $r$ passando por $A$ e $O A$ e $O A^{\prime}$ são segmentos congruentes entre si, sendo que $O$ é o ponto de interseção da reta perpendicular com $r$. 
A rotina de uso desta transformação no GeoGebra é: constrói-se uma reta $r$ a partir de dois pontos, a qual será o eixo de reflexão; depois constrói-se um ponto $A$ que não pertence a reta $r$. Com a ferramenta Reflexão em Relação a uma Reta, seleciona-se primeiro o ponto $A$ e depois a reta $r$ e assim obtém-se o ponto $A^{\prime}$, que é o refletido de $A$. Na Figura 9 tem-se a construção feita no GeoGebra.

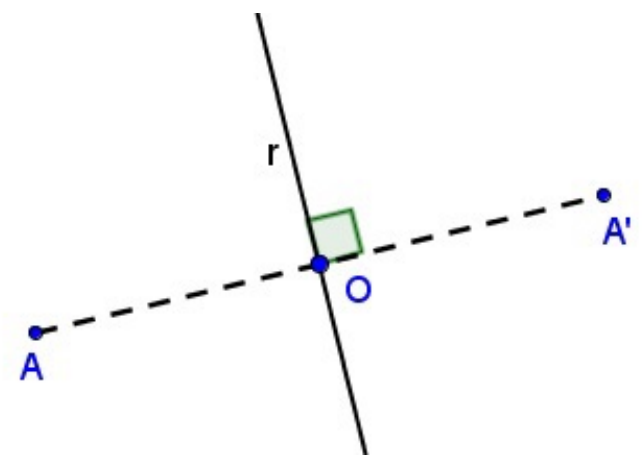

Figura 9: Reflexão do ponto $A$ segundo a reta $r$.

A reflexão segundo uma reta é uma isometria (isto se demonstra) e, portanto, transforma cada figura $F$ em outra $F^{\prime}$, congruente à primeira. Vamos ver como isto funciona no GeoGebra: constróise uma reta $r$ e um triângulo $A B C$, tal que os vértices $A, B$ e $C$ estão no mesmo semiplano em relação à reta $r$. Com a ferramenta Reflexão em Relação a uma Reta seleciona-se o triângulo $A B C$ e depois a reta $r$ e obtém-se o triângulo $A^{\prime} B^{\prime} C^{\prime}$, o refletido do primeiro. A Figura 10 ilustra esta transformação. Movimentando um dos vértices do triângulo $A B C$ com a ferramenta Mover, o triângulo refletido também se modifica, mas se mantém sempre o refletido do primeiro triângulo.

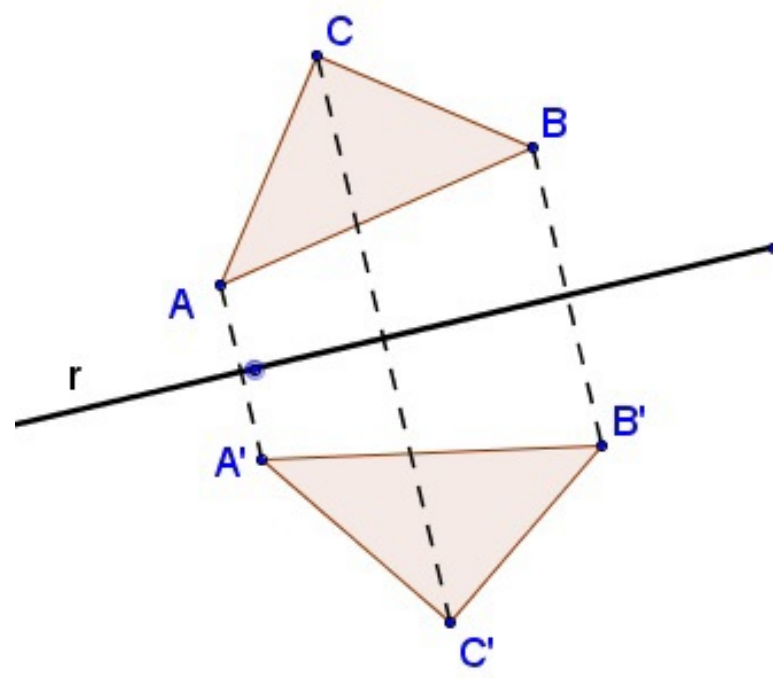

Figura 10: Reflexão do triângulo $A B C$ segundo a reta $r$. 
- A transformação de rotação

Dado um ponto fixo $O$ no plano e um ângulo de medida $\alpha$, a rotação de centro $O$ e amplitude $\alpha$ é a transformação que a cada ponto $A$ do plano $\Pi$ associa o ponto $A^{\prime}$ de forma tal que:

- se $A=O$ então $A^{\prime}=O$.

- se $A$ é diferente de $O$ então o ângulo formado pelas semiretas $O A$ e $O A^{\prime}$ tem medida $\alpha$, sendo que ângulo é medido no sentido anti-horário da semireta $O A$ para a semirreta $O A^{\prime}$.

- os segmentos $O A^{\prime}$ e $O A$ são congruentes.

O procedimento para fazer a rotação do ponto $A$ em torno do ponto $O$ sob um ângulo $\alpha=45^{\circ}$ no GeoGebra é o seguinte: constrói-se o ponto $O$ e depois o ponto $A$. Com a ferramenta Rotação em Torno de um Ponto por um Angulo, seleciona-se o ponto $A$ e, em seguida, o ponto $O$ e de imediato o software disponibiliza uma caixa de diálogo contendo as opções para escolha da amplitude do ângulo e o sentido da medição - escolhe-se um ângulo de medida $\alpha=45^{\circ}$ e escolhe-se o sentido anti-horário de rotação - e como resultado tem-se o ponto $A^{\prime}$. A Figura 11 ilustra o resultado do procedimento feito.

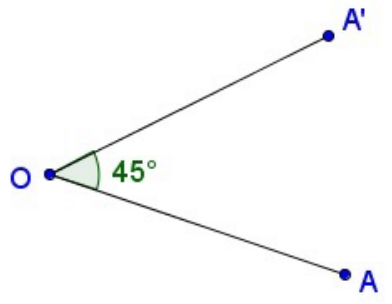

Figura 11: Rotação do ponto $A$ em torno do ponto $O$.

A rotação também é uma isometria (isto se demonstra), portanto transforma uma figura $F$ em outra $F^{\prime}$, congruente à primeira. A rotação de um triângulo, no Geogebra, assim funciona: constrói-se um ponto $O$ (centro de rotação) e com a ferramenta Polígono constrói-se o triângulo $A B C$; escolhese a ferramenta Rotação em Torno de um Ponto por um Ângulo, seleciona-se o triângulo $A B C$ e o ponto $O$, e escolhe-se como medida de ângulo, por exemplo, $\alpha=60^{\circ}$ e escolhe-se sentido antihorário, e assim obtém-se o triângulo $A^{\prime} B^{\prime} C^{\prime}$ que é o rotacionado do triângulo $A B C$. A Figura 12 ilustra esta transformação. 


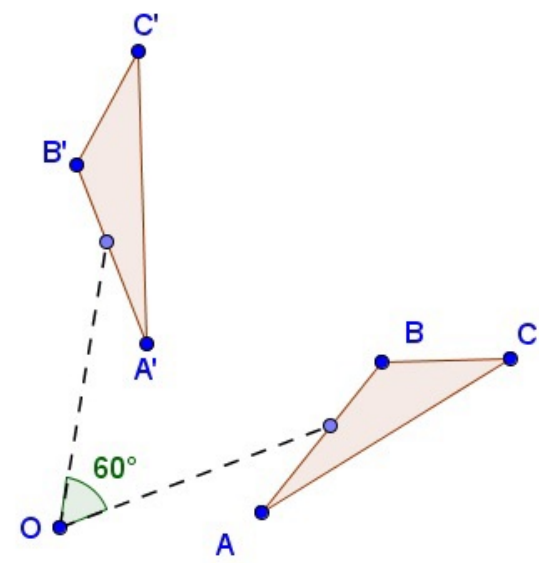

\begin{tabular}{|l|c|}
\hline Rotação em Torno de um Ponto & $\times$ \\
\hline Ângulo & \\
$60^{\circ}$ & a \\
\hline
\end{tabular}

- sentido anti-horário

sentido horário

Figura 12: Rotação do triângulo $A B C$ em torno do ponto $O$.

Pode-se fazer sucessivas rotações de uma figura em torno de um mesmo ponto, segundo um mesmo ângulo, obtendo-se assim uma coleção de figuras rotacionadas e todas congruentes à figura inicial. A Figura 13 ilustra o resultado de sucessivas aplicações da rotação em torno do ponto $B$ (neste caso o ponto $B$ é o centro de rotação), segundo um ângulo de $45^{\circ}$ e no sentido anti-horário, que inicia com a rotação do triângulo $A B C$. Aplicando a ferramenta Mover em qualquer um dos vértices do triângulo inicial $A B C$, todos os vértices correspondentes sofrem a mesma movimentação. Na construção ilustrada na Figura 13, escolheu-se cores diferentes para cada triângulo, criando um efeito tipo 'hélices de um cata-vento'.

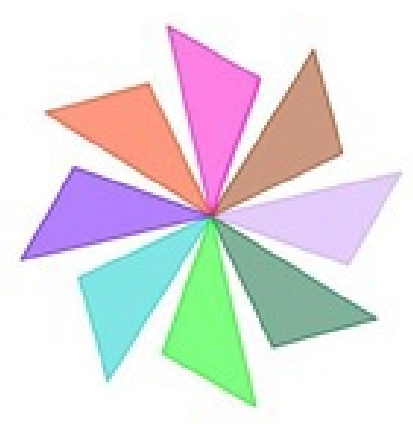

Figura 13: Sucessivas rotações em torno de um mesmo ponto.

\section{A concepção e a implementação da experiência didática}

Na concepção da experiência, a questão norteadora foi: de que forma professores de Matemática se apropriam do software GeoGebra para trabalhar com transformações geométricas e mosaicos? A questão foi respondida através de pesquisa de caráter qualitativo. Por meio de filmagens foram feitos registros dos momentos de trabalho dos professores; as produções feitas pelos professores 
foram gravadas e junto com os protocolos de construção se constituíram em material de análise; as produções dos alunos desses professores também fizeram parte de nossa coleta de dados.

A organização da pesquisa tomou como referência a Engenharia Didática. Este método de pesquisa é composto de quatro fases assim distribuídas: Análises Prévias; Concepção e Análise A priori; Experimentação; Análise A posteriori e Validação da Experiência ([5]). Nas análises prévias tratamos de três dimensões: a dimensão cognitiva, ao trazer as ideias de Vygotsky sobre aprendizagem e desenvolvimento; a dimensão epistemológica e também cognitiva, ao trazer o trabalho de Duval que discute o quanto os sistemas de representações semióticas são constitutivos do saber matemático e a sua importância no processo de aprendizagem; a dimensão didática, ao referenciar as diretrizes dos PCN (Parâmetros Curriculares Nacionais) e ao fazer a análise dos livros didáticos, bem como ao discutir o potencial da tecnologia no ensino da Matemática.

No que segue vamos nos concentrar na concepção e na implementação da experiência, trazendo um pouco das análises a priori e a posteriori. A experiência foi implementada através de oficina e dela participaram sete professoras de Matemática e uma responsável pelo laboratório de informática da rede municipal de Sombrio-SC. Dentre as tarefas propostas havia a realização de uma prática, na qual a professora deveria criar atividades para sua sala de aula, tratando de transformações geométricas com uso do software GeoGebra. A oficina se organizou em seis encontros. Nos quatro primeiros tratamos: da familiarização com o software; da construção de pavimentações regulares e semirregulares; da reprodução de mosaicos; da construção de mosaicos de Escher. No início de cada assunto foi feita a apresentação de um vídeo ${ }^{6}$ de sensibilização ${ }^{7}$. O quinto encontro ficou destinado para a organização das práticas das professoras e o último para a apresentação dos resultados.

Como material de apoio utilizamos o CD Mídias Digitais I ${ }^{8}$ (Figura 14) constituído de sete módulos, dentre os quais destacamos os módulos I e II como os principais recursos consultados pelas professoras. O CD serviu como fonte de pesquisa para os conceitos básicos de Geometria e fonte de sugestões de atividades para serem desenvolvidas com os alunos, utilizando o GeoGebra.

$\mathrm{O}$ primeiro encontro ficou destinado às atividades coletivas de familiarização com o software. Foram abordados os conceitos básicos da Geometria Plana, tais como, ponto, reta, segmento; foram explorados o menu das transformações geométricas e também alguns dos outros recursos (retas paralelas e perpendiculares, ângulo, triângulo, paralelogramo, mediatriz, bissetriz, círculo). Ao abordar os conceitos da Geometria Plana, tivemos como objetivo revisá-los, pois as professoras já tinham conhecimento sobre o assunto. Esta revisão se fez por meio da utilização de um roteiro de construção de figuras no GeoGebra.

\footnotetext{
${ }^{6}$ Arte GeoGebra http://www.youtube.com/watch?v=5fHFi3xbCfQ\&feature=related, Tesselation slideshow http: //www.youtube.com/watch?v=5-3tOa9CPb0 , Igrejas Matrizes da Quarta Colônia de Imigração Italiana do Rio Grande do Sul (em DVD - UNIFRA - Centro Universitário Franciscano), Escher e a Geometria http://www. youtube.com/watch?v=6aRFy73cZxY, Matemática em toda parte, Construção/ Pavimentação com polígonos http: //www.youtube.com/watch?v=y__0a7TDbfs, Escher Style http://www.youtube.com/watch?v=h2AWKgU0cN4.

${ }^{7}$ Segundo Moran ([13]), um bom vídeo é interessante para introduzir um novo assunto, para despertar a curiosidade, a motivação para novos temas.

${ }^{8}$ Este CD faz parte do material a ser utilizado nas disciplinas de Mídias Digitais I e Prática Pedagógica I do Curso de Especialização "Matemática, Mídias Digitais e Didática". Este curso também possui um site que apresenta possibilidades de utilização de diferentes softwares e objetos de aprendizagem para o ensino e aprendizagem da Matemática. Os conteúdos de matemática a serem trabalhados são: geometria euclidiana, transformações geométricas no plano, geometria analítica, funções e gráficos. O site foi implementado pelas bolsistas: Fernanda Abreu Lima, Larissa Weyh Monzon e Mariângela Torre Dias, alunas do curso de Licenciatura em Matemática da UFRGS em 2009 e por Marina Menna Barreto (tutora à distância do curso), sob a coordenação da professora Maria Alice Gravina do Instituto de Matemática da UFRGS e com financiamento da UAB/MEC.
} 


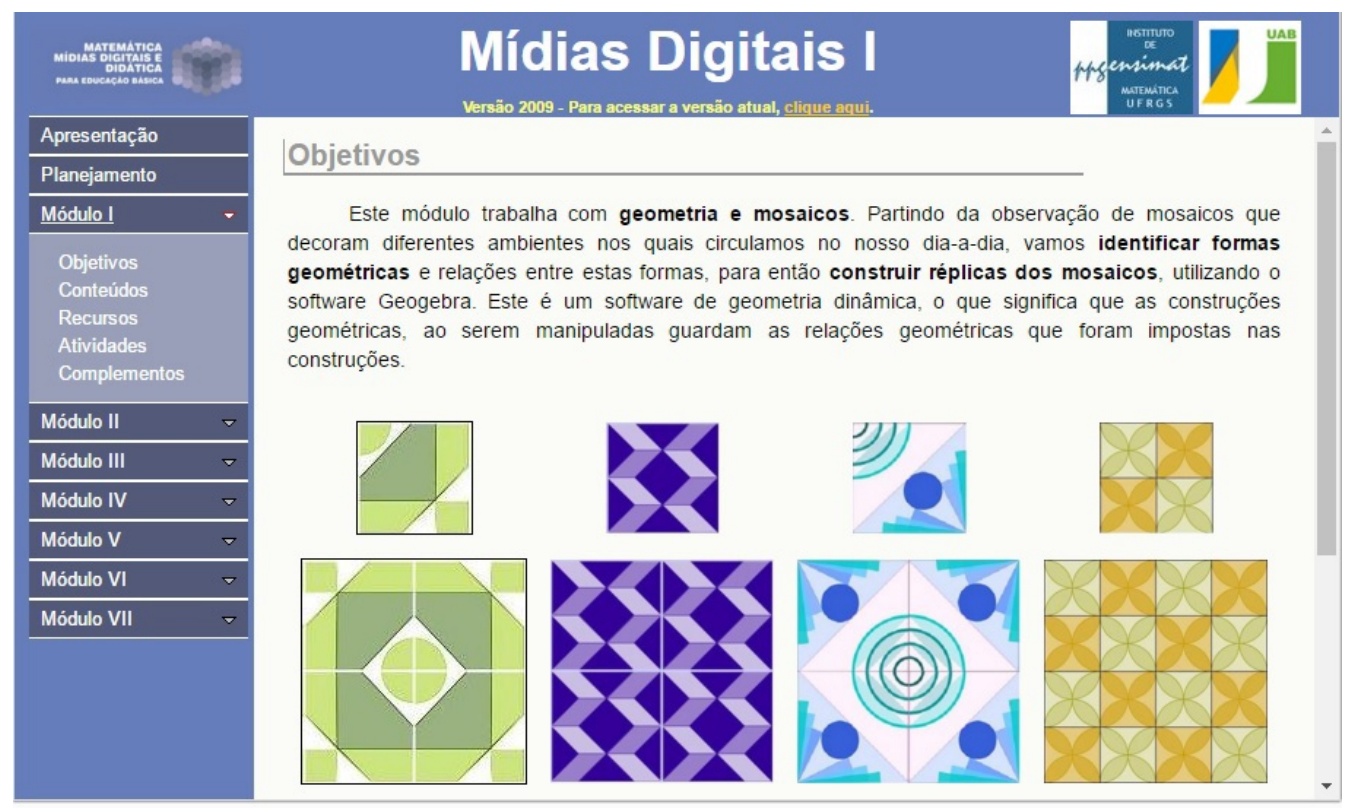

Figura 14: Interface do CD Mídias Digitais I

Fonte: http://www6.ufrgs.br/espmat/disciplinas/midias_digitais_I/.

Em relação à exploração do menu das transformações geométricas planas, esperávamos que as professoras reconhecessem a conservação de algumas propriedades das figuras sujeitas aos movimentos de reflexão, translação ou rotação. Esperávamos que, usando o dinamismo de figuras que se tem no GeoGebra e que é revelador de invariantes geométricos, elas reconhecessem que tais transformações preservam as distâncias e os ângulos, o paralelismo e o perpendicularismo. Mas foi ainda com bastante hesitação nos procedimentos de construção que ao final do primeiro encontro as professoras apresentaram suas primeiras produções.

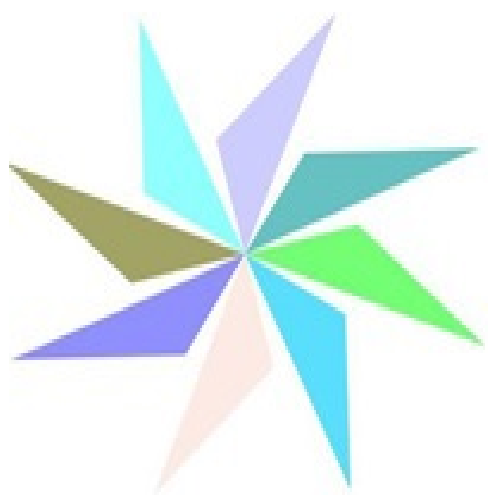

Figura 15: Construção no GeoGebra da professora M. 
No segundo encontro foi feita uma exploração coletiva das ferramentas Polígonos e Polígonos Regulares do GeoGebra. A atividade também exigia o uso do menu das transformações para construir uma pavimentação regular e uma semirregular. Nessa atividade o objetivo foi de que as professoras estabelecessem a diferença no uso das ferramentas Polígono e Polígono Regular. Quando se utiliza a ferramenta Polígono Regular, obtém-se figura que, sob a ação da ferramenta Mover, não se deforma, diferentemente daquilo que acontece quando se usa a ferramenta Polígono. Quanto ao conhecimento matemático, teve-se como objetivo a identificação das condições necessárias para a construção de uma pavimentação com polígonos regulares. Foi após esta atividade de construção que foi apresentado o Teorema de Kepler $^{9}$ : ,

Existem exatamente onze maneiras de se cobrir o plano utilizando-se exclusivamente polígonos regulares sujeitos às condições: a) se dois polígonos regulares intersectamse, então essa interseção é um lado ou um vértice comum; b) a distribuição dos polígonos regulares ao redor de cada vértice é sempre a mesma. (Alves Dalcin,1999, p.12).

Com a utilização do teorema de Kepler e fazendo uso da notação ${ }^{10}$ das 11 possibilidades de pavimentações com polígonos regulares (a saber, $(3,12,12),(4,6,12),(4,8,8),(6,6,6),(4,4,4,4)$, $(3,6,3,6),(3,4,6,4),(3,3,3,3,6),(3,3,3,4,4),(3,3,4,3,4)$ e $(3,3,3,3,3,3))$, cada professora teve como tarefa construir uma das pavimentações.

A professora C. fez sua pavimentação, ilustrada na Figura 16, utilizando a ferramenta Polígono Regular para construir o hexágono regular e depois, usando vetores determinados por vértices do hexágono regular, aplicou a transformação de translação. Entre os hexágonos regulares coloridos de vermelho, formaram-se triângulos equiláteros, os quais a professora coloriu de azul. Observamos que sua proposta de mosaico não está incluída na categoria dos semi-regulares do teorema de Kepler, pois a distribuição dos polígonos em torno dos vértices não se mantém sempre a mesma (em alguns vértices a distribuição é $(6,3,3,6)$, em outros é $(6,3,6,3)$ ou ainda $(3,6,6,3))$.

\footnotetext{
${ }^{9}$ A primeira pessoa a exibir os mosaicos semirregulares foi J. Kepler, em um trabalho publicado em 1619, no qual está este teorema. Alves e Dalcin demonstram este teorema apresentando todas as possibilidades de formação dos mosaicos regulares e semirregulares. (Alves e Dalcin, 1999).

${ }^{10} \mathrm{~A}$ notação $(3,12,12)$ indica que em cada vértice tem-se o encontro de três polígonos regulares: um triângulo e dois dodecágonos regulares.
} 


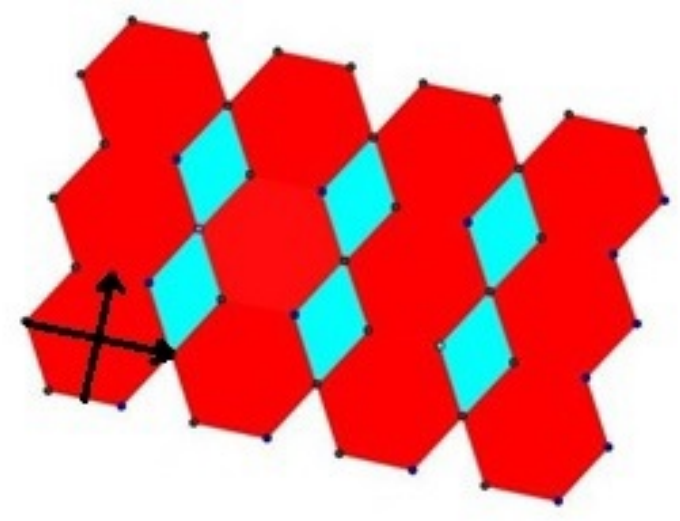

Figura 16: Construção da professora C.

Na Figura 17, temos a produção da professora D que resultou em mosaico que respeita o arranjo $(3,3,4,3,4)$.

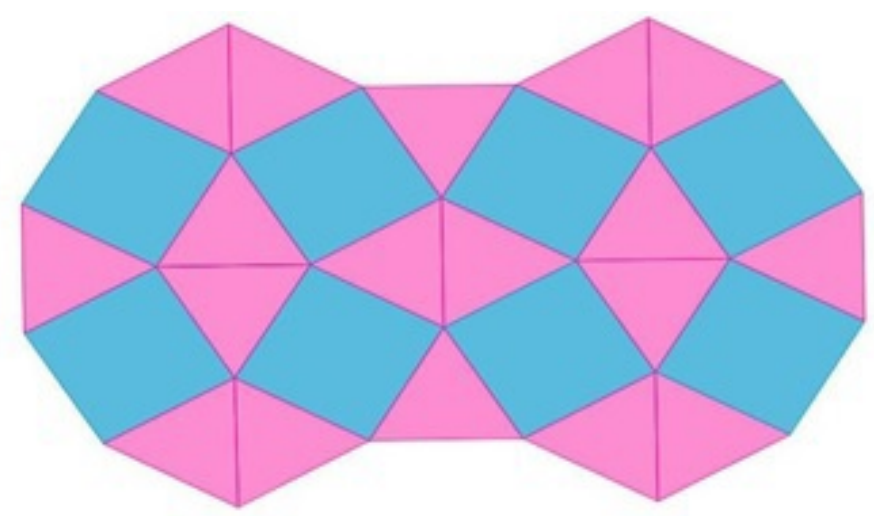

Figura 17: Construção da professora D.

Para o terceiro encontro foi proposta a reprodução de mosaico que tivesse sido visto em algum local da cidade. Nesta atividade foi solicitado uma descrição dos elementos geométricos utilizados na construção; comentários sobre o local onde foi visto o mosaico; a construção do mosaico no GeoGebra; considerações sobre a construção realizada, informando sobre as dificuldades encontradas, tanto de Geometria quanto de utilização do software GeoGebra. Na Figura 18 tem-se uma destas reproduções, feita pela professora $\mathrm{D}$. 


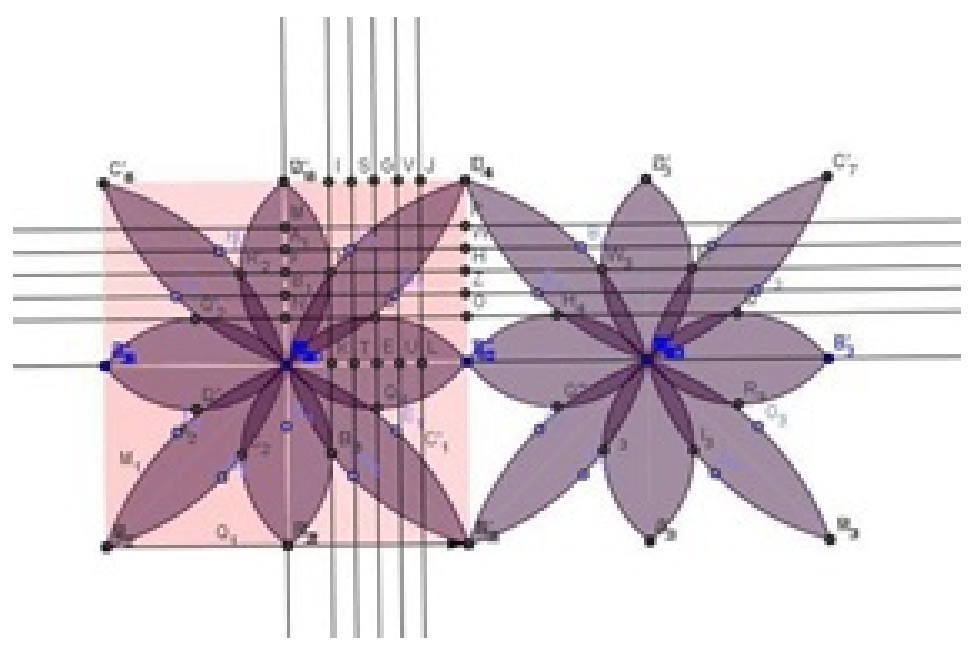

Figura 18: Reprodução de Mosaico da professora D.

A construção começa com um quadrado e depois foram determinados sucessivos pontos médios, iniciando com aquele correspondente ao do lado do quadrado. Feixes de retas paralelas passando por estes pontos foram construídos, na tentativa de criar uma malha quadriculada que ajudasse na construção das pétalas do mosaico. Esta estratégia não funcionou como esperado e então a professora solicitou nossa ajuda. Sugerimos então que utilizasse uma ferramenta que ainda não havia sido utilizada - o Arco Circular definido por Três Pontos. Ela selecionou os três primeiros pontos para produzir o primeiro arco de círculo, com sucesso, e usando a transformação de reflexão segundo uma reta ela conseguiu fazer a primeira pétala da flor. E foi usando sucessivas reflexões segundo retas que foram construídas as demais pétalas, de modo a completar o padrão do mosaico. Feito o primeiro mosaico, foi com a transformação de translação que ela construiu, ao lado, o segundo mosaico. Foi possível observar que a professora D, ao longo dos encontros, foi aumentando o nível de complexidade de suas construções. Isso indica um amadurecimento na apropriação das ferramentas do software e no domínio dos conceitos geométricos em questão. Ao final de sua reprodução, foi aplicada a ferramenta Mover e o mosaico manteve suas propriedades geométricas.

Na Figura 19, vemos a produção da professora L. Ela iniciou sua construção com um segmento $\overline{A B}$ e após construiu dois círculos com centros em $A$ e $B$, respectivamente, e raio com medida igual à do segmento $\overline{A B}$. Foram determinados os pontos $C$ e $D$ de interseção dos círculos e traçadas as retas $\overleftrightarrow{B C}, \overleftrightarrow{B D}, \overleftrightarrow{A C}, \overleftrightarrow{A D}$. Usando os pontos de interseção dessas retas com os círculos, foram construídas retas paralelas e isto resultou em uma malha triangular. Na malha foram construídos alguns hexágonos e, após, com rotações e reflexões, foram construídos os demais. Foi observado que a professora utilizou conceitos básicos da Geometria para a construção de seu mosaico, e, além disso, sua produção preservou as propriedades geométricas ao aplicar-se a ferramenta Mover. 


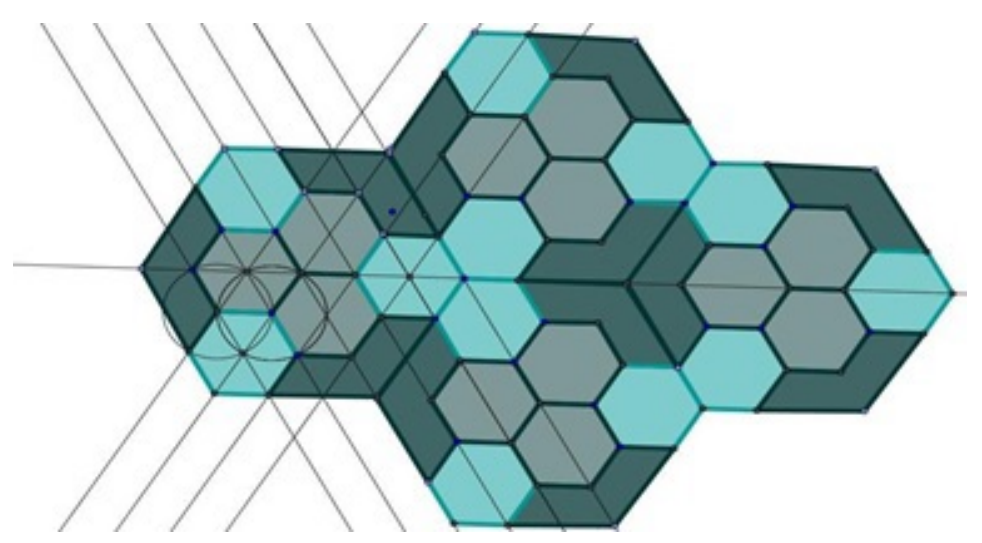

Figura 19: Reprodução do Mosaico da professora L.

No quarto encontro foram explorados os mosaicos de Escher. Este artista utilizou padrões geométricos e transformações geométricas no seu trabalho com mosaicos. Com o GeoGebra é possível fazer a construção de pavimentações com movimentos no estilo de Escher, conforme ilustra a sequência de procedimentos dada na Figura 20. Inicia-se com um hexágono regular, diferentes 'recortes' são rotacionados em torno de vértices do hexágono (destacados como recortes verde, azul e vermelho) e assim obtém-se o polígono padrão inicial; segue-se então com a aplicação da transformação de rotação sobre este polígono.

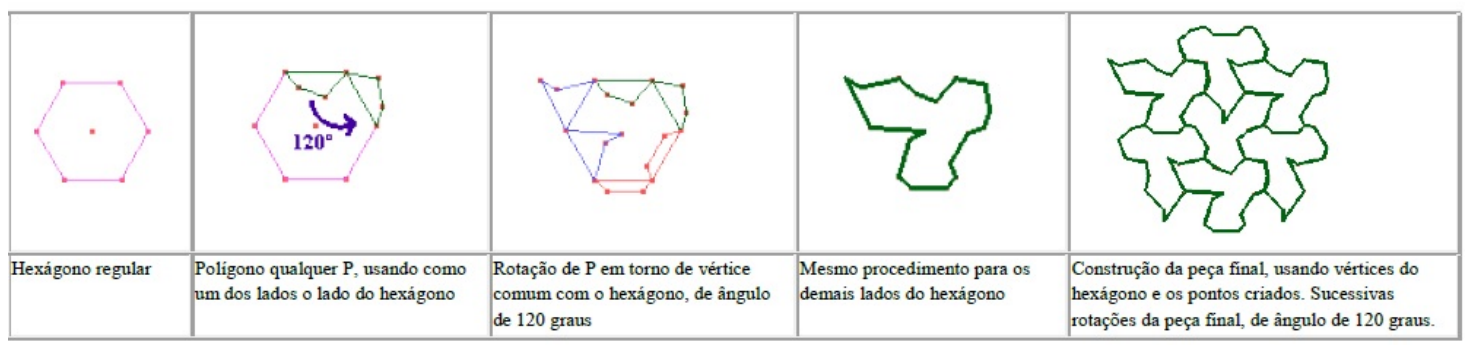

Figura 20: Construção do Mosaico. Fonte: CD Mídias Digitais I.

Na primeira atividade, que fez uso de applets com mosaicos dinâmicos (disponíveis no CD Midias Digitais I), foi solicitado que as professoras participantes identificassem o polígono padrão inicial, bem como a transformação geométrica utilizada para produzir a pavimentação. Na segunda atividade, elas foram convidadas a produzir mosaicos no estilo de Escher. Na Figura 21 tem-se a produção de uma das professoras - uma pavimentação que muda dinamicamente seu desenho, conforme são movimentados vértices do polígono padrão inicial, colocado em destaque. 


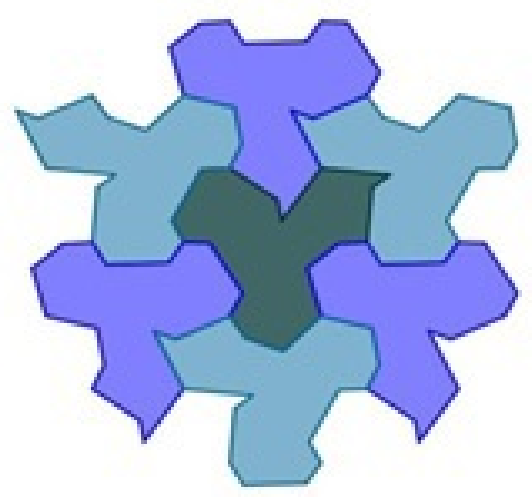

Figura 21: Construção de "mosaico em movimento" da professora L.

O quinto encontro foi reservado para organizar a apresentação das experiências que as professoras fizeram com seus alunos. Relembramos que no início da oficina foi combinado com as professoras que elas iriam aplicar com seus alunos os conhecimentos adquiridos durante a formação. $\mathrm{Na}$ realização de suas práticas as professoras propuseram atividades similares aquelas desenvolvidas na formação. Mas também surgiram algumas ideias diferentes: relacionar os mosaicos com a arte do patchwork; fazer reproduções de habitações de animais, como por exemplo colmeias; reproduzir algumas formas geométricas encontradas na natureza, as flores por exemplo. No último encontro, as professoras relataram suas experiências.

Diríamos que ao longo da realização da oficina, houve muita participação e muito interesse por parte das professoras. Elas constantemente indagavam sobre os objetivos na utilização do vídeo de sensibilização, sobre a utilização do software, sobre a pertinência da sequência de atividades e sobre as alternativas para ensinar Geometria na escola. Na perspectiva de Vygotsky, a troca de experiência e a interação social fizeram com que as professoras pudessem internalizar os conhecimentos trabalhados na oficina, e nisso as indagações e discussões foram fundamentais. Em diversos momentos da oficina, houve a necessidade da nossa intervenção como professora mediadora. No primeiro encontro observamos as dificuldades iniciais e, a partir de nossa intervenção, constatamos os progressos das professoras quanto ao uso dos recursos do GeoGebra. Procuramos atuar na zona de desenvolvimento proximal, ou seja, fizemos intervenções necessárias para que o conhecimento, que era potencial nas professoras-alunas, se transformasse em real.

Os conceitos relativos as diferentes transformações geométricas foram introduzidos através do GeoGebra e de forma a integrar Arte e Matemática. Através da aplicação da sequência de atividades foi proporcionada uma gradativa aquisição de conhecimento sobre o GeoGebra; nenhuma das professoras, bem como seus alunos, conhecia o software. Além disso, na perspectiva de [7], o software permitiu a mobilização de diferentes registros de representação, bem como os tratamentos e as conversões de registros.

\section{Considerações finais}

Nossa proposta de capacitação docente proporcionou às professoras participantes a familiarização com o software GeoGebra, a oportunidade de revisar os conceitos básicos de Geometria Plana e 
uma introdução ao estudo das transformações geométricas (este um assunto pouco trabalhado na escola) em situação que integrou arte e geometria.

A característica dinâmica do software permitiu às professoras trabalharem as transformações geométricas em contexto concreto-abstrato - com o uso de diferentes ferramentas foram construídas situações geométricas correspondentes as diferentes transformações e com o uso da ferramenta Mover propriedades geométricas puderam ser observadas e assim novos conceitos foram sendo aprendidos.

A utilização do GeoGebra proporcionou a experimentação, a simulação, o questionamento e a análise de situações geométricas. Tal vivência entusiasmou as professoras e fez com que concluíssem que fazendo uso GeoGebra é possível trabalhar as transformações geométricas na escola - foi esta prática que elas fizeram com seus alunos. A introdução na formação de um tal software de geometria dinâmica fez com que as professoras repensassem suas práticas.

Mas entendemos que, ao fazer uso de um software, o professor não pode perder de vista o que pretende ensinar.

O software não deve ser utilizado apenas para fazer uma aula diferente, mas sim para que o aluno aprenda matemática. Nisso os sistemas dinâmicos de representação veiculados através da tecnologia digital podem muito ajudar e foi neste espírito que foi implementada a proposta de formação apresentada neste artigo.

\section{Referências}

[1] Baquero, R. Vygotsky e a aprendizagem escolar. Porto Alegre: Artes Médicas, 1998.

[2] Borba, M., Villarreal, M. Humans-with-Media and the reorganization of mathematical thinking. New York: Springer, 2005.

[3] Borba, M., Penteado, M. G. Informática e Educação Matemática. São Paulo: Autêntica, 2007.

[4] Brasil. Parâmetros Curriculares Nacionais: Matemática. DF: Ministério da Educação e do Desporto, 1998.

[5] Carneiro, V. C. G. Engenharia Didática: um referencial para ação investigativa e para formação de professores de Matemática. Zetetike. Campinas, v.13,p. 85-118, 2005.

[6] Duval, R. Semiósis e Pensamento Humano: Registros Semióticos e Aprendizagens intelectuais. São Paulo: Livraria da Física, 2009.

[7] Duval, R. Ver e Ensinar a Matemática de outra forma. São Paulo: Proem, 2011.

[8] Gravina, M. A. Os ambientes de geometria dinâmica e o pensamento hipotético-dedutivo. Tese de Doutorado, Porto Alegre: UFRGS, 2001.

[9] Gravina, M. A., Barreto, M. Mídias Digitais I. Material Didático. Curso de Especialização: Matemática, Mídias Digitais e Didática para a Educação Básica. Porto Alegre, UAB/IM/UFRGS, 2009. Disponível em: www6.ufrgs.br/espmat/disciplinas/midias_digitais_I/.

[10] Lima, E. L. Isometrias. Rio de Janeiro: SBM, 2007.

[11] Mariotti, M. A. Artifacts and signs after a Vygotskian perspective. Disponível em http://www. mendeley.com/research/artifacts-signs-after-vygotskian-perspective-role-teacher-1/. Acesso em 15 dez. 2011. 
[12] Moll, L. C. Vygostky e a educação: Implicações pedagógicas da psicologia sócio-histórica. Porto Alegre: Artes Médicas, 1996.

[13] Moran, J. M. O vídeo na Sala de Aula. Comunicação \&̇ Educação. ECA-Ed.Moderna, p27-35. jan/abr 1995.

[14] Moysés, L. Aplicações de Vygotsky à Educação Matemática. São Paulo: Papirus Editora, 2010.

[15] Radford, L. Introducción. Semiótica Y Educación Matemática. Revista Latino Americana en Matematica Educativa . México, Distrito Federal. p.7-21. 2006.

Margarete Medeiros

IFC - Campus Sombrio $<$ margarete.farias@ifc-sombrio.edu.br>

Maria Gravina UFRGS <gravina@mat.ufrgs.br>

Recebido: 2015

Publicado: 2015 